UDK 528.344

\title{
NETWORK RTK PERFORMANCE ANALYSIS: A CASE STUDY IN LATVIA
}

\author{
Didzis DOBELIS ${ }^{1,2}$, Jānis ZVIRGZDS ${ }^{1,2}$ \\ ${ }^{1}$ Riga Technical University, Department of Geomatics, Kipsalas iela 6B, Riga, LV-1048, Latvia \\ ${ }^{2}$ Latvian Geospatial Information Agency, Ojara Vaciesa iela 43, Riga, LV-1004, Latvia \\ E-mail: didzis.dobelis@rtu.lv (corresponding author)
}

Received 31 May 2016; accepted 12 September 2016

\begin{abstract}
Nowadays the RTK (Real Time Kinematic) method for positioning is used in daily life by different consumers for many purposes. Several different RTK correction techniques are used, starting from single site to network approaches. The GNSS market is filled with receivers from different manufacturers and different capabilities. In this paper we assess the stability of the reference station network transmitted RTK correction. Two different surveying class GNSS receivers in combination with four varied RTK correction techniques under diverse observation conditions are analyzed. This study has been conducted in Latvia, where state wide permanent GNSS reference station network has been maintained since year 2005.
\end{abstract}

Keywords: CORS Network, iMAX, MAX, Real Time Kinematic, RTK stability, Single Site, VRS.

\section{Introduction}

In last three decades after the RTK (Real-Time Kinematic) - a proven method of positioning in real-time at the cm-level was introduced in early 1990's - the establishment of CORS (Continuously Operating Reference Station) networks has significantly grown. CORS networks are widely used in many areas of economy because of possibilities to significantly reduce costs and time from user point of view. In most of European countries there is at least one CORS network. Usually these networks can be divided in two fractions: the first one - maintained and funded by governmental bodies, and the second one - commercial networks, maintained as business projects. But in view of used technologies and performance indicators there are not and should not be significant differences among them.

CORS network is based on the use of several widely spaced permanent stations. Depending on the implementation, positioning data from the permanent stations is regularly sent to a central processing server. On demand from RTK user terminals, which transmit their approximate location to the central server, the central server calculates and transmits correction information or corrected position to the RTK user terminal. The benefit of this approach is an overall reduction in the number of RTK base stations required. Depending on the implementation, data may be transmitted over cellular radio links or other data transmission techniques. Several different techniques of RTK correction transmission to CORS network user have been developed and widely used within professionals.

For transmission of CORS network RTK corrections to users in real-time, the commonly used techniques are MAX (correction service which utilizes Master-Auxiliary Concept), I-MAX (Individualized MAX), FKP (Flächen Korrektur Parameter = Area Correction Parameters) and VRS (Virtual Reference Station). For detailed description about these techniques reader is refereed to Takac and Zelzer (2008). There are significant differences between these methods and therefore different quality RTK solutions are achieved (Leica Geosystems 2012). Many scientific studies have been done intended to assess the accuracy and precision of the correction techniques used in CORS network approach. In Berber, Arslan (2013) the network RTK transmission techniques (MAX, iMAX, FKP and VRS) were investigated to determine which suits the best for surveying applications. The research regarding on same RTK transmission techniques used for coordinate obtaining under different elevation angles and in 4 specific locations (open, semiopen, wooden, urban) has been discussed by Gumus (2016). The research conducted in Sweden permanent station network SWEPOS points out, the RMS error 
dependence of elevation angle setting (Jämtnäs et al. 2010). Also the influence of future GNSS (Galileo and Compass) has been predicted. In the study carried out by Grejner-Brzezinska et al. (2005), the accuracy of NRTK correction techniques at different measuring configurations has been investigated. Approximately $2 \mathrm{~cm}$ horizontal and $4 \mathrm{~cm}$ vertical accuracy were obtained. Martin and McGovern (2012) have tested the accuracy and performances of Network RTK applications. Horizontal and vertical accuracies were $22 \pm 8 \mathrm{~mm}$, and $29 \pm 14 \mathrm{~mm}$ respectively. A set of metrics has been defined to characterize the performance of network RTK: availability, time-to-first-fix, precision, accuracy, solution integrity and moving average filtering (Bisnath et al. 2013). The robust analysis of network RTK derived heights are presented in Bae et al. (2015) and some similarities on methodology for data collection can be observed between Bae et al. (2015) and methodology introduced later in this paper. The accuracy of network RTK correction techniques is the one measure, but the stability of this accuracy and factors which affects it is the direction where this paper has focused.

The aim of this paper is to analyze the performance of Latvian CORS network using these commonly used network RTK correction techniques and investigate the framework conditions which one of these techniques could be the best depending of the arguments like: geographic location, surroundings, etc. In addition, the objective is to determine whether there is correlation between continuously observed position displacement by RTK and changes in satellite conditions or communication link status. Also the network RTK correction techniques are compared to single site technique.

The first CORS network in Latvia called "LatPos" was established in year 2005. In year 2016 network consists of 25 permanent base stations widely spaced

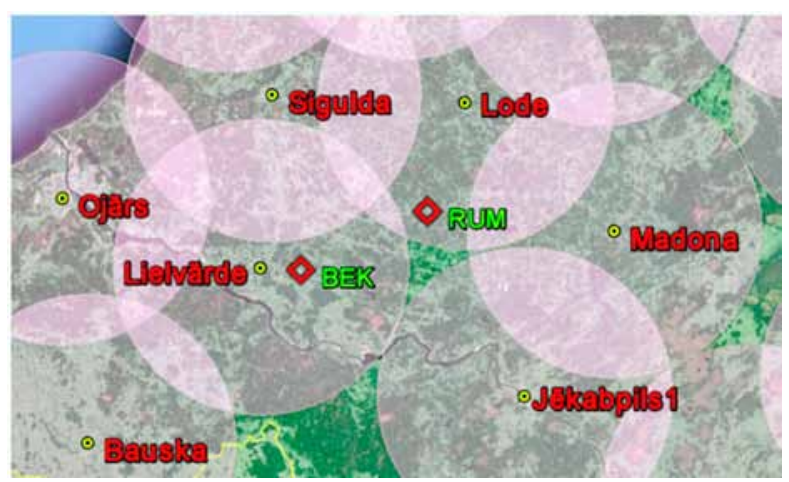

Fig. 1. Locations of RUM and BEK in relation to LatPos stations in territory of Latvia. LatPos is maintained by governmental body - Latvian Geospatial Information Agency. As the author has been involved in LatPos administration process and support for RTK users, it has turned out that frequently there are misunderstandings in LatPos user community which RTK correction type has to be used under dependencies of many factors.

\section{Methods}

In this study four different RTK point location information obtaining methods have been used. Three network-based solutions for RTK measurements used: MAX, iMAX and VRS. Also the Single site RTK solution was used. All of them transmitted to rover receiver by RTCM 3.x. message generated at Latvian permanent GNSS base station network (LatPos) software.

Following methodology was selected because of previously made studies, where information of registered rover user's data to LatPos network were analyzed. Previously made studies showed that there should be guidelines developed and recommendations given which RTK solution should be used due to ambient factors. It has turned out that many LatPos users are using RTK network solutions even rover receiver connects to network outside of its coverage - that is not how the benefit of CORS network should be properly used. It should be noticed, that LatPos network is maintained for full coverage of whole country, but there are few places closely to borders of country where network RTK solutions are not available and only single site solution can be used.

Data for this study has been collected in two different geographic locations and surroundings in territory of Latvia. Both locations were selected in places, where network RTK corrections can be used. Location No. 1 (RUM) were selected in place where distances to LatPos permanent stations (labels colored in red) are in comparison very similar - rover receivers are located in the middle of network corrections generated area (see Fig. 1). Location No. 2. (BEK) were selected in place where distances to LatPos permanent stations are more varied - this gives opportunity to investigate the single site RTK solution dependence of RTK baseline length and also the network RTK solutions are generated under different conditions. The purple colored circles are $35 \mathrm{~km}$ buffer areas of LatPos permanent stations.

In each location data collected simultaneously with three rover receivers installed on separate tripods close to each other (1-2.5 m). Rover receivers used: two Leica manufactured receivers Leica Viva with 
antennas GS12 and one Trimble manufactured receiver Trimble R8. Installed receivers at location BEK can be seen in Figure 2.

At both locations the surrounding can be evaluated as good for GNSS observations - no obstructing elements as tall trees or other elements that could cause significant multipath effects or obstruct signal. Also mobile internet coverage at both locations were stable that ensures low RTK correction data age on receivers transmitted from LatPos central server.

In order to analyze each correction type, their correlation and dependence of elevation cut-off angle settings, five measurement sessions were carried out at each location. Settings for each receiver and session are conducted in Table 1. Time span for each session was 40 min with continuously stored measurements with $1 \mathrm{sec}$ rate - as resulting 2400 determined positions with each receiver.

The observations from NAVSTAR GPS and GLONASS satellite systems were used.

Table 1. Rover receiver settings in relation to session No.

\begin{tabular}{|c|c|c|c|}
\hline $\begin{array}{c}\text { S. } \\
\text { No. }\end{array}$ & \multicolumn{3}{|c|}{ Rover receiver } \\
\hline & Leica Viva $^{\star} 1$ & Leica Viva $^{\star} 2$ & Trimble R8 \\
\hline 1. & SITE(0) & $\operatorname{SITE}(0)$ & $\operatorname{SITE}(10)$ \\
\hline 2. & $\operatorname{SITE}(10)$ & $\operatorname{SITE}(0)$ & $\begin{array}{c}\text { NETW- } \\
\text { iMAX(10) }\end{array}$ \\
\hline 3. & NETW-MAX(10) & $\begin{array}{c}\text { NETW- } \\
\text { iMAX(10) }\end{array}$ & $\operatorname{VRS}(10)$ \\
\hline 4. & $\operatorname{VRS}(10)$ & $\operatorname{SITE}(15)$ & $\operatorname{SITE}(15)$ \\
\hline 5. & $\operatorname{VRS}(0)$ & NETW-MAX(0) & $\operatorname{VRS}(10)$ \\
\hline
\end{tabular}

Note: ${ }^{\star}$ SITE - Single site correction from nearest base station. NETW-MAX - MAC concept network RTK correction.

NETW-iMAX - Individualized MAX concept network RTK correction. VRS - Virtual Reference Station network RTK correction.

$*(0.10$ or 15$)-$ elevation cut-off angle.

\section{Results and discussion}

As three rover receivers simultaneously were set to collect data for period of $40 \mathrm{~min}$ on each observation session that ensures powerful analyze of stability of each RTK correction type and their correlation to each other. The quality indicators such as standard deviation and maximum amplitude of $\sim 2400$ obtained positions for each coordinate can be derived.

The RTK baseline lengths at each location were different. At location RUM baseline length to nearest LatPos station "Lode" was $\sim 27 \mathrm{~km}$, when single site corrections were used. At location BEK baseline length to nearest LatPos station "Lielvārde" was $\sim 11 \mathrm{~km}$.
When network RTK corrections such as NETWMAX, NETW-iMAX and VRS were used, LatPos software generates so called "cell" form several permanent stations to calculate correction parameters for rover receiver. LatPos stations used for network RTK correction at each location and area of "cell" (polygon colored in light blue) can be seen in Figure 3a, b.

\subsection{RTK quality indicators derived from obtained positions}

The quality indicators such as standard deviation $(\sigma)$ and maximum amplitude (A) of 2400 obtained positions for each coordinate, north (N), east (E) and normal height $(\mathrm{H})$ at each location were calculated. Full information off them has been assembled in Table 2.

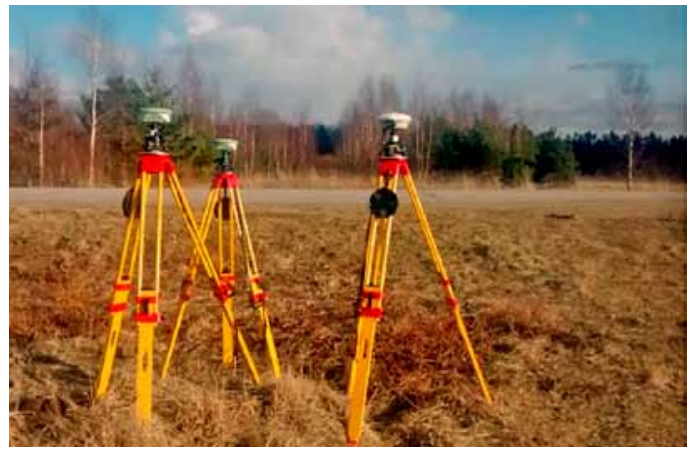

Fig. 2. Installed receivers at location BEK

(a)

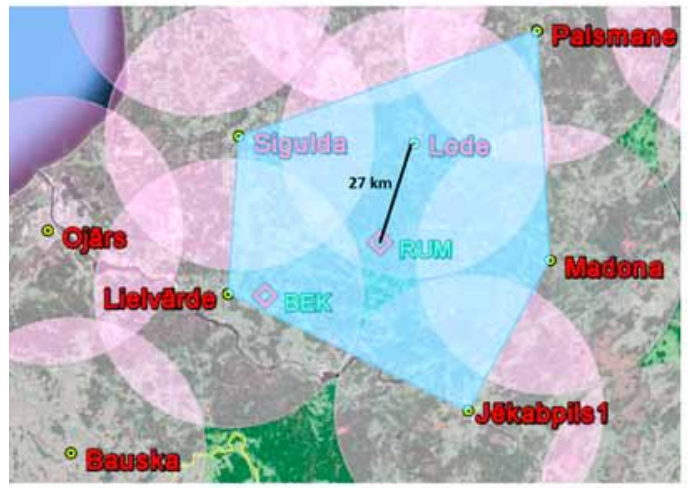

(b)

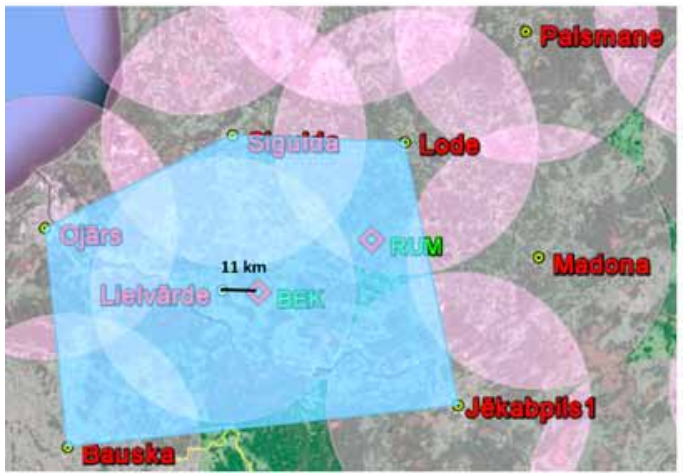

Fig. 3. LatPos software generated "cell" for network RTK correction parameter calculation on rover receivers at location RUM (a) and BEK (b) 
As it has been noticed by many other studies done before, the single site solution acts much better at shorter baseline lengths. In this study it can be clearly seen in data from Leica Viva rover receivers on session No. 1. and No. 2. If at the location RUM approximate baseline length were $27 \mathrm{~km}$, then at location BEK it was about $11 \mathrm{~km}$ as result the maximum amplitude of coordinate series were decreased about $20-50 \%$. Also

Table 2. Standard deviation and maximum amplitude by rover receiver and session

\begin{tabular}{|c|c|c|c|c|c|c|c|}
\hline \multicolumn{8}{|c|}{ Leica Viva*1 } \\
\hline \multirow{2}{*}{$\begin{array}{c}\text { S. } \\
\text { No. }\end{array}$} & & \multicolumn{3}{|c|}{ Location - RUM } & \multicolumn{3}{|c|}{ Location - BEK } \\
\hline & & $\mathrm{N}$ & $\mathrm{E}$ & $\mathrm{H}$ & $\mathrm{N}$ & $\mathrm{E}$ & $\mathrm{H}$ \\
\hline \multirow[t]{2}{*}{1.} & $\sigma$ & 4.1 & 4.3 & 8.1 & 4.1 & 2.2 & 7.2 \\
\hline & A & 33 & 28 & 52 & 20 & 12 & 42 \\
\hline \multirow[t]{2}{*}{2.} & $\sigma$ & 6.2 & 3.3 & 15.0 & 3.4 & 2.2 & 6.0 \\
\hline & A & 37 & 24 & 77 & 20 & 14 & 40 \\
\hline \multirow[t]{2}{*}{3.} & $\sigma$ & 4.4 & 2.5 & 9.1 & 3.3 & 2.1 & 4.2 \\
\hline & A & 25 & 16 & 49 & 19 & 12 & 27 \\
\hline \multirow[t]{2}{*}{4.} & $\sigma$ & 2.4 & 3.7 & 6.7 & 3.0 & 2.1 & 5.1 \\
\hline & A & 17 & 18 & 38 & 18 & 14 & 38 \\
\hline \multirow[t]{2}{*}{5.} & $\sigma$ & 4.3 & 2.4 & 5.0 & 3.8 & 1.9 & 4.6 \\
\hline & A & 27 & 15 & 32 & 24 & 14 & 25 \\
\hline \multicolumn{8}{|c|}{ Leica Viva 2} \\
\hline \multirow{2}{*}{$\begin{array}{c}\text { S. } \\
\text { No. }\end{array}$} & & \multicolumn{3}{|c|}{ Location - RUM } & \multicolumn{3}{|c|}{ Location - BEK } \\
\hline & & $\mathrm{N}$ & E & $\mathrm{H}$ & $\mathrm{N}$ & $\mathrm{E}$ & $\mathrm{H}$ \\
\hline \multirow[t]{2}{*}{1.} & $\sigma$ & 4.9 & 3.7 & 9.4 & 4.1 & 3.2 & 6.9 \\
\hline & A & 30 & 25 & 55 & 24 & 14 & 43 \\
\hline \multirow[t]{2}{*}{2.} & $\sigma$ & 5.7 & 4.3 & 11.6 & 3.5 & 2.5 & 6.1 \\
\hline & A & 39 & 26 & 73 & 22 & 13 & 37 \\
\hline \multirow[t]{2}{*}{3.} & $\sigma$ & 3.8 & 2.4 & 6.1 & 2.2 & 1.6 & 5.2 \\
\hline & A & 23 & 15 & 34 & 14 & 11 & 33 \\
\hline \multirow[t]{2}{*}{4.} & $\sigma$ & 6.2 & 3.6 & 10.3 & 2.4 & 1.5 & 4.7 \\
\hline & A & 34 & 26 & 65 & 15 & 9 & 31 \\
\hline \multirow[t]{2}{*}{5.} & $\sigma$ & 3.7 & 2.4 & 5.3 & 2.6 & 1.8 & 4.4 \\
\hline & $\mathrm{A}$ & 31 & 12 & 35 & 14 & 11 & 29 \\
\hline \multicolumn{8}{|c|}{ Trimble R8 } \\
\hline \multirow{2}{*}{$\begin{array}{c}\text { S. } \\
\text { No. }\end{array}$} & & \multicolumn{3}{|c|}{ Location - RUM } & \multicolumn{3}{|c|}{ Location - BEK } \\
\hline & & $\mathrm{N}$ & $\mathrm{E}$ & $\mathrm{H}$ & $\mathrm{N}$ & $\mathrm{E}$ & $\mathrm{H}$ \\
\hline \multirow[t]{2}{*}{1.} & $\sigma$ & 6.9 & 3.9 & 10.7 & 8.9 & 3.9 & 19.2 \\
\hline & $\mathrm{A}$ & 43 & 24 & 76 & 46 & 27 & 97 \\
\hline \multirow[t]{2}{*}{2.} & $\sigma$ & 9.6 & 4.7 & 9.1 & 6.3 & 4.3 & 14.0 \\
\hline & A & 58 & 29 & 55 & 56 & 50 & 97 \\
\hline \multirow[t]{2}{*}{3.} & $\sigma$ & 3.7 & 3.8 & 7.7 & 8.0 & 3.4 & 11.2 \\
\hline & A & 24 & 24 & 50 & 48 & 20 & 64 \\
\hline \multirow[t]{2}{*}{4.} & $\sigma$ & 7.7 & 3.7 & 10.8 & 4.9 & 3.0 & 11.5 \\
\hline & A & 42 & 23 & 68 & 36 & 18 & 72 \\
\hline 5. & $\sigma$ & 6.7 & 3.5 & 10.8 & 4.1 & 2.7 & 8.7 \\
\hline & A & 47 & 21 & 64 & 32 & 16 & 54 \\
\hline
\end{tabular}

Note: All values in table are given in millimeters. the standard deviation for each coordinate were decreased significantly. However this cannot be clearly noticed in data from Trimble R8 receiver. Conversely if comparing values from session No. 1. at both locations derived with Trimble R8 receiver, having shorter baseline length it acts slightly worse than having longer baseline length. But if checking the values from session No. 4 with Trimble R8 receiver where elevation cut-off angle was set at 15 degrees, some enhancements due to dependence of baseline length can be observed.

Generally, in all conditions Trimble R8 receiver were gathered the worst results in all sessions if comparing to both Leica Viva receivers. It has to be noted that Trimble R8 receiver also were the oldest one, so it should be the main factor affecting its performance.

Comparing all different RTK correction solutions smallest amplitude in coordinate series are derived with Leica Viva receiver used NETW-MAX network correction (Leica Viva ${ }^{\star} 1$ session No. 3, location BEK). Also the Leica Viva 2 receiver on session No. 4 at location BEK with single site correction shows respectable results.

\subsection{Homogeneity of RTK corrections}

In order to compare how both Leica Viva receivers act when configured with equal settings and using same correction type, simultaneously observed coordinate series of session No. 1 at location BEK and RUM are assembled in Figure 4.

As shown in Figure 4 the correlation between both Leica Viva receivers with simultaneously observed positions under equal conditions is very close, however at the same time also some shifts among them on each coordinate axis can be observed. This could be explained by precision of first fixed position and despite the fact that both receivers were installed with distance up to $2.5 \mathrm{~m}$ from each other, there could be impact of visible satellites at the same time also.

\subsection{RTK coordinate shifts relation to satellite visibility}

In order to check whether there is correlation between continuously observed position displacement - shifts on coordinate axis and changes in number of visible satellites, the visual analysis of obtained coordinate series of each receiver was carried out. The best correlation can be seen on Trimble R8 receiver collected observations from session No. 1. at location BEK (Fig. 5). As noticed before, that also is the same data set where the largest amplitude and standard deviation on each coordinate axis was determined. 
In Figure 5 the number of visible satellites varies from 15 up to 18 satellites, but as it can be seen (from beginning of the session and for period close to the

(a)

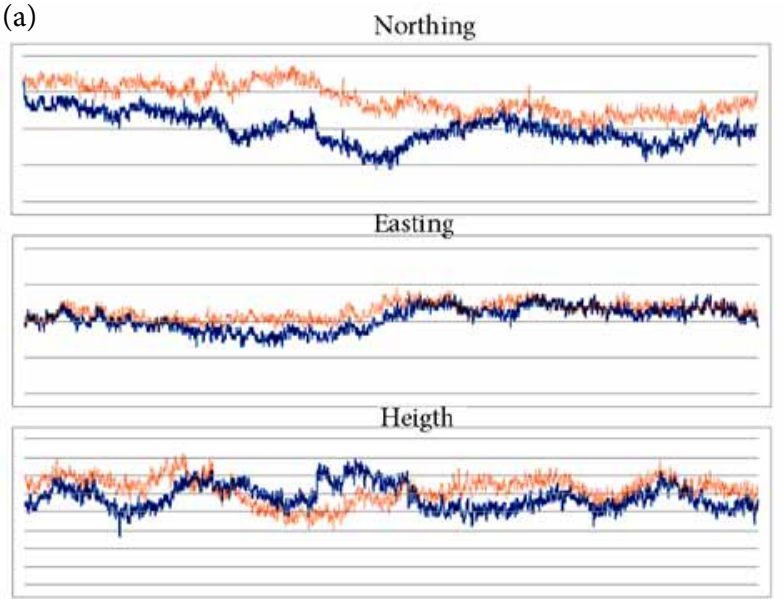

(b)

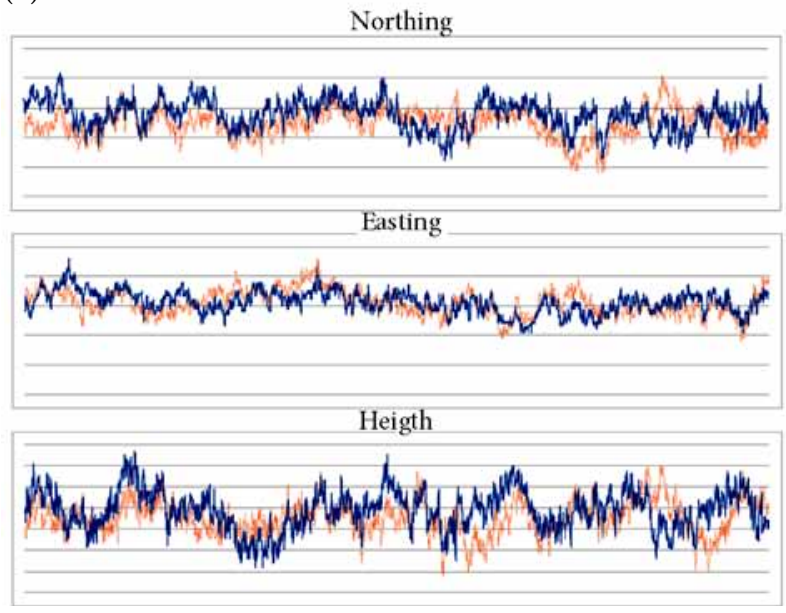

Fig. 4. Coordinate time series correlation between both Leica Viva receivers of session No. 1 at location BEK (a) and RUM (b). (All gridlines are $10 \mathrm{~mm}$ ).

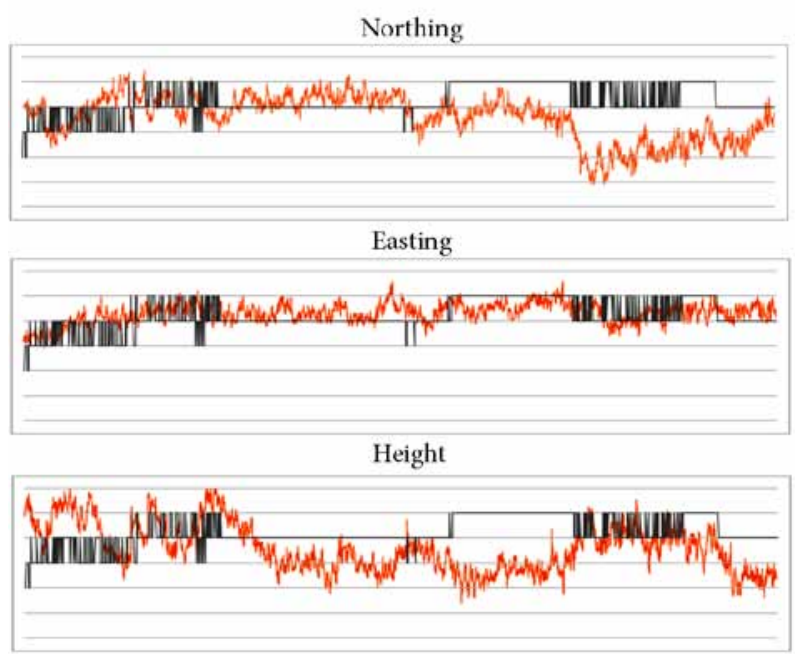

Fig. 5. Correlation between continuously observed position displacements - shifts on coordinate axis and changes in number of visible satellites at location BEK, session No.1 observed with Trimble R8 receiver end of the session), probably some satellite at the low elevation angle were obstructed by local surrounding as result it shows up and gets invisible several times. These kind of satellite visibility "jumps" causes the greatest shifts on coordinate axis.

\subsection{RTK horizontal coordinate repeatability}

Significant factor which is in interest of CORS network users is coordinate repeatability. In this study the mean coordinate values of each receiver at each location are compared with respect to used RTK solution (See Figs 6 and 7).

As extracted form Figures 6 and 7. The mean horizontal coordinate repeatability for both Leica Viva

(a)

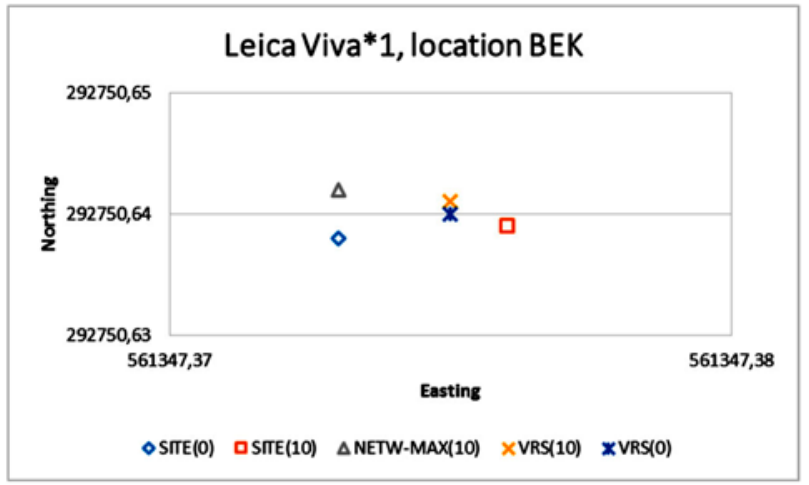

(b)

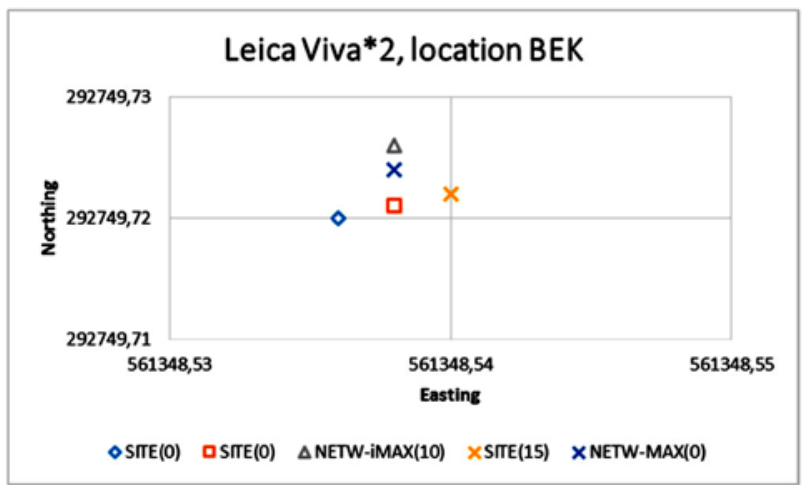

(c)

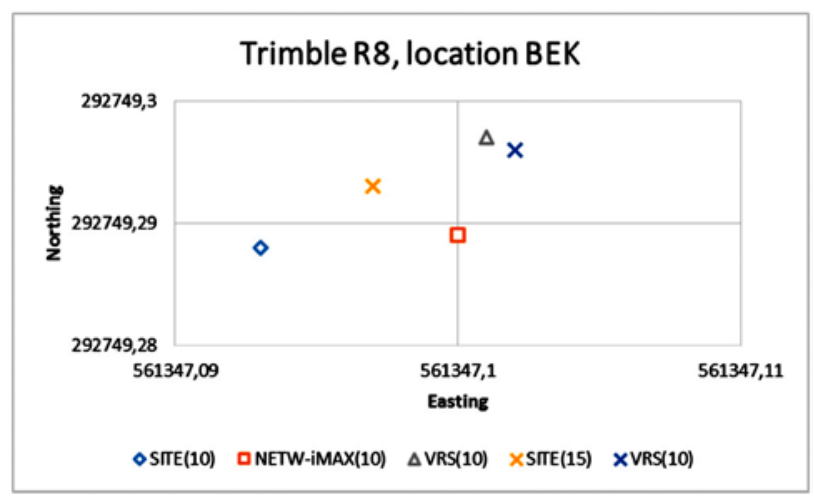

Fig. 6. Horizontal coordinate repeatability at location BEK by receiver models (a), (b) and (c) with respect to used RTK solution 
receivers on each location is in range of up to $10 \mathrm{~mm}$, but for Trimble R8 receiver the mean horizontal coordinate repeatability with respect to used RTK solution varies up to $40 \mathrm{~mm}$. Possible reasons for so bad performance of Trimble $\mathrm{R} 8$ receiver should be studied further.

\section{Conclusions}

The method chosen in this study - when three GNSS receivers are set to collect data simultaneously in same location is powerful when analyzing the obtained results because of fact that behavior of GNSS observation errors is the same for each receiver.

When two identical GNSS receivers are used simultaneously under equal settings, the clear

(a)

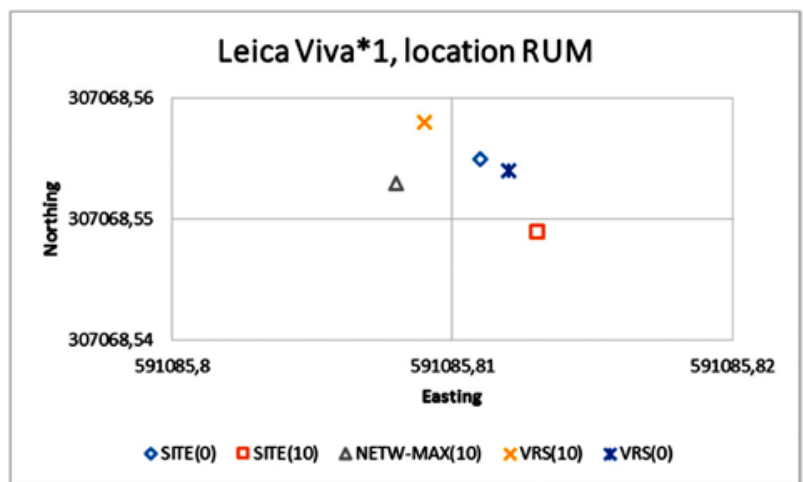

(b)

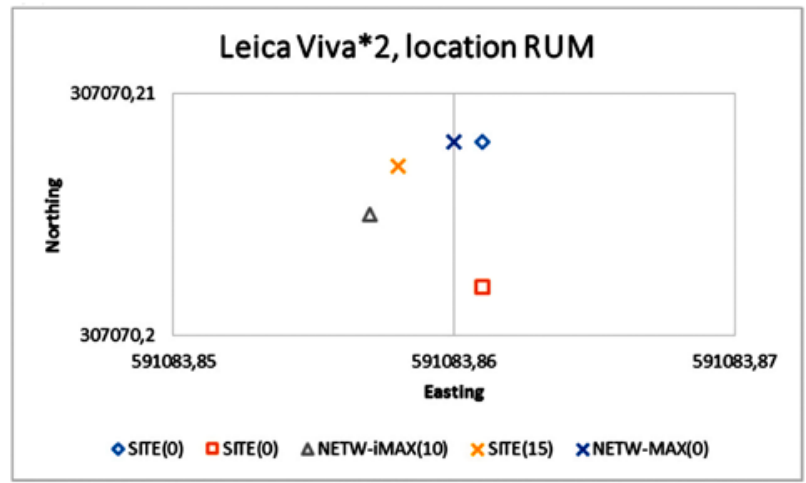

(c)

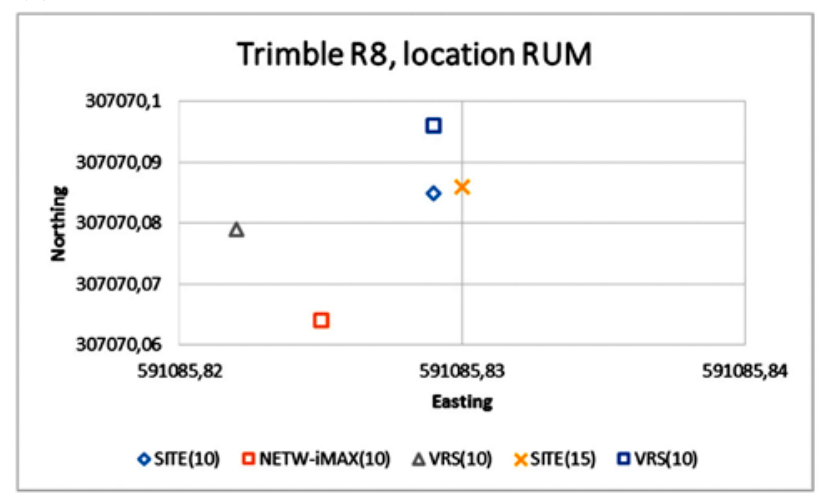

Fig. 7. Horizontal coordinate repeatability at location RUM by receiver models (a), (b) and (c) with respect to used RTK solution correlation between obtained results can be seen, but also some unknown differences are observed.

The correlation between continuously observed position displacements - shifts on coordinate axis and changes in number of visible satellites have been noticed in this study.

As gathered from results, the well-known theories of different RTK network solutions performance have also confirmed in usage of LatPos generated RTK solutions. At the same time the RTK network users should be very cautious and critical on obtained results when using old manufactured GNSS receiver.

\section{References}

Bae, T.-S.; Grejner-Brzezinska, D.; Mader, G.; Dennis, M. 2015. Robust analysis of network-based real-time kinematic for GNSS-derived heights, Sensors 15: 27215-27229. http://dx.doi.org/10.3390/s151027215

Berber, M.; Arslan, N. 2013. Network RTK: a case study in Florida, Measurement 46: 2798-2806. http://dx.doi.org/10.1016/j.measurement.2013.04.078

Bisnath, S.; Saeidi, A.; Wang, J.-G.; Seepersad, G. 2013. Evaluation of network RTK performance and elements of certification - a Southern Ontario case study, Geomatica 67: 243-251. http://dx.doi.org/10.5623/cig2013-050

Grejner-Brzezinska, D. A.; Kashani, I.; Wieglosz, P. 2005. On accuracy and reliability of instantenous network RTK as a function of network geometry, station separation, and data processing strategy, GPS Solutions 93: 179-193.

Gumus, K. 2016. A research on the effect of different measuring configurations in Network RTK applications, Measurement 78: $334-343$.

http://dx.doi.org/10.1016/j.measurement.2015.10.022

Jämtnäs, L.; Suhna, J.; Emardson, R.; Jonsson, B. 2010. Quality assessment of network-RTK in SWEPOS ${ }^{\text {Tix }}$ network of permanent GNSS stations, FIG Congress 2010, 11-16 April 2010, Sydney, Australia.

Leica Geosystems. 2012. RTK networks - different methods. System 1200 Newsletter, 2012, No. 53, SmartNet, EU.

Martin, A.; Mcgovern, E. 2012. An evaluation of the performance of network RTK GNSS services in Ireland, International Federation of Surveyors (FIG) Working Week, 6-10 May 2012, Rome, Italy.

Takac, F.; Zelzer, O. 2008. The relationship between network RTK solutions MAC, VRS, PRS, FKP and i-MAX, in Proceedings of the $21^{\text {st }}$ International Technical Meeting of the Satellite Division of The Institute of Navigation (ION GNSS 2008), September 2008, Savannah, GA, 348-355.

Didzis DOBELIS. Ph.D student, Riga Technical University, Department of Geomatics.

Senior expert at GNSS permanent base stations division, Latvian Geospatial Information Agency.

Jānis ZVIRGZDS. Associate Professor, Doctor. Riga Technical University, Department of Geomatics.

Head of GNSS permanent base stations division, Latvian Geospatial Information Agency. 